\title{
From hot to cold - the temperature dependence on rock deformation
} processes: an introduction

\author{
E. Gomez-Rivas ${ }^{1,2 *}$, R.W.H. Butler ${ }^{1}$, D. Healy ${ }^{1}$ and G.I. Alsop ${ }^{1}$ \\ ${ }^{1}$ Department of Geology and Geophysics, School of Geosciences, King’s College, University of Aberdeen, \\ Aberdeen AB24 3UE, United Kingdom \\ ${ }^{2}$ Departament de Mineralogia, Petrologia i Geologia Aplicada, Facultat de Ciències de la Terra, Universitat de \\ Barcelona, Martí i Franquès s/n, 08028 Barcelona, Spain \\ *Corresponding author: Enrique Gomez-Rivas (e.gomez-rivas@ub.edu)
}

\begin{abstract}
Understanding rock deformation processes in solid Earth materials, from the crystal to the tectonic plate scale, is essential for characterising the evolution of the lithosphere and for predicting how rocks behave in the subsurface. Temperature is a key parameter that determines what rock deformation processes are active and therefore how tectonic structures form. Moreover, it controls the migration of fluids and melt in the Earth's crust that lead to phase transformations and changes in rock rheology. This special issue gathers a collection of research papers following the 21st International Conference on Deformation Mechanisms, Rheology and Tectonics, which was held in Inverness (Scotland) in April-May 2017, organised by the University of Aberdeen. These contributions provide a significant advance in the study of rock deformation and fluid/melt migration at multiple crustal levels, from deformation bands near the Earth's surface to shear zones in partially molten rocks in the lower crust. In this introductory article, we first provide an overview of how temperature controls deformation mechanisms and then introduce the collection of research papers
\end{abstract}


ordered from those analysing deformation processes occurring at high temperatures to contributions reporting deformation at shallow crustal conditions.

\section{Introduction}

The past few decades have seen an increasing interest in the study of deformation processes and structures in solid Earth materials. These studies embrace all scales, from intracrystalline to intercontinental, and in recent years concepts in rock deformation have also been applied to other materials, such as water ice, and include liquid phases. Increasingly there has been a special emphasis placed upon analysing the mechanical behaviour of anisotropic and multiphase rocks, and how deformation processes interact with fluid and melt migration. Understanding how structures develop at multiple scales, from shape and crystal preferred orientations at the microscale to large-scale faults, folds and shear zones, is necessary for characterising the evolution of the lithosphere. This is important in order to unravel processes associated with mountain building and to predict the behaviour of rock in the subsurface. Very often these processes do not operate in isolation, but interact with one another, thereby leading to complex feedback effects that make their study and interpretation difficult. For example, temperature is a key parameter controlling the activation of different deformation mechanisms, from cataclasis to dislocation glide and diffusion creep, and fundamentally determines how rocks deform. The migration of fluids and melt in the Earth's crust is also controlled by temperature, leading to phase transformations and changes in rock rheology that in turn influence the active deformation processes.

Relating the ways rocks deform to the development of tectonic structures has been studied for well over 100 years (see review by Law and Johnson, 2010). In the 1880s, first Lapworth $(1884)$ and then Teall $(1885 ; 1918)$ established that thrusts and shear zones represented locations where deformation localised and that localisation was facilitated by 
recrystallisation on the grain scale. These initial insights built upon understanding of industrial processes, especially in metallurgy, that were pioneered by Sorby in the mid $19^{\text {th }}$ century (e.g., Sorby, 1858). Indeed, Lapworth's coining of the term "mylonite" relates to the steel mills of the late industrial revolution. While the controlling conditions on metal production and performance were readily investigated experimentally, in geology work only began in earnest in the middle of the twentieth century (e.g., Griggs, 1940). Relating experimental rock deformation to microstructure, a key step for deducing how deformation processes can be identified in the geological record, demanded the use of electron microscopy. These advances, pioneered by Christie and coworkers (e.g., Christie et al., 1964) and more widely applied in the 1970s (e.g., Tullis et al., 1973; White, 1973), again arose principally from the application of techniques developed in metallurgy and ceramics. The disparate strands of experimental insights, the identification of microstructures and their use as evidence for the operation of specific crystal-scale mechanisms, upscaling these observations and deductions to infer how tectonic structures develop and evolve, were all drawn together in the influential text of Nicolas and Poirier (1976). The first conference in the biennial series of peripatetic conferences now known as "Deformation Mechanisms, Rheology and Tectonics" ran in Leiden in the same year (Lister et al., 1977).

This Special Issue follows the $21^{\text {st }}$ conference in the series, organised by the University of Aberdeen (Scotland), and held at the Eden Court Theatre in Inverness, from $30^{\text {th }}$ April to $4^{\text {th }}$ May 2017. This conference was attended by 116 delegates from around the world, who presented and discussed research in the fields of rock deformation, structural geology, rheology, tectonics, microstructures, rock physics and interactions between deformation and metamorphic/diagenetic reactions. The conference included a series of preconference excursions, a mid-conference plenary excursion and a post-conference fieldtrip, all of them to classic locations for structural geology in the Scottish Highlands. The outcrops 
included those that inspired Lapworth, Teall, and then White. All the sites are protected for their geoheritage, with descriptions available in Mendum et al. (2009).

Derived from the Inverness conference, this Special Issue is a collection of 18 articles that together provide a significant advance in the study of rock deformation and fluid/melt migration at multiple crustal levels, from deformation bands near the Earth's surface to shear zones in partially molten rocks in the lower crust. These contributions tackle fundamental questions using state-of-the-art techniques, including rock microstructure characterisation and image analysis, geothermometry and geothermobarometry, geomechanical tests and numerical simulations, among others. At the same time, most of these studies are underpinned by fieldwork, which remains central to structural geology. Additionally, they link rock behaviour across multiple processes and scales, providing new insights into the deformation of the continental crust. In this preface we first briefly review and summarise temperature controls on deformation mechanisms, and then present the contents of the special issue from high to low temperature deformation conditions.

\section{How temperature controls deformation mechanisms: an overview}

Temperature and pressure, together with differential stress and strain rate, are the main parameters that determine how minerals and rocks deform. At low temperature and shallow crustal levels, deformation is normally dominated by brittle behaviour while ductile flow takes place at higher temperature (and effective confining pressure), and therefore generally at deeper levels (with the exception of a few minerals, such as halite and water ice, among others). Rock deformation also depends on the mineral assemblage and spatial distribution of their components, as for example grain size and grain size distribution, orientation of crystal lattice, porosity, permeability, and the presence and composition of interstitial fluids. Rock deformation events commonly enhance transport of elements and 
mineral reactions (Wheeler, 2018), and thus temporally coincide with growth of minerals during diagenesis, metamorphism and hydrothermal activity. Reactions between metamorphic minerals, as well as their chemical compositions under assumed equilibrium conditions, allow estimation of the evolution of a rock volume through time using $P-T-D-t$ (pressure-temperature-deformation-time) paths (Brown, 1993). The temperature and pressure conditions at which reactions related to tectonic events take place can be estimated with geothermometers and geobarometers, some of which are presented in this volume (see section 3).

Brittle deformation has historically been described as a temperature-independent process that strongly depends on pressure and presence of fluids (Blenkinsop, 2000). On the contrary, ductile flow (also termed viscous or viscoplastic flow) is determined by thermallyactivated deformation mechanisms including dislocation glide and creep, twinning, kinking and diffusion creep, and also by associated processes such as intracrystalline recovery and dynamic recrystallisation. Pressure-solution is a special process, since it normally operates in systems at low temperature but high differential stress and in the presence of fluids, but it can also be active under a wide variety of thermal conditions (Rutter, 1983). A summary of the main mechanisms controlling rock deformation and how temperature determines their activation is presented below, as an introduction to the articles included in this special issue. For complete reviews of deformation mechanisms, we refer the reader to Passchier and Trouw (2005), Karato (2012) or Hobbs and Ord (2015).

Brittle deformation is the dominant deformation mechanism in the shallow crust, where temperatures are typically low. Brittle deformation operates by the nucleation and propagation of fractures as well as slip along existing discontinuities, e.g., fractures, bedding planes, faults, etc. (Fig. 1a). Brittle failure of a rock occurs when it cannot elastically sustain the stress it is subjected to and the rock aggregate breaks, separating it in two or more pieces. 
Griffith (1921) proposed that stress is concentrated at the tips of microscopic cracks and flaws, such as those existing in the crystal lattice, grain boundaries, pores or second-phase inclusions, in a way that they propagate to become larger cracks under relatively low stress. This phenomenon explains why rocks indeed fail under differential stresses that are orders of magnitude lower than the theoretical stress needed to break atomic bonds of rock-forming minerals. Microcracks, also termed microfractures, can open in different ways, from directions perpendicular to the crack wall (tensile cracks) to those parallel to it (shear cracks), or combinations of both. For a thoughtful review of microcracks the reader is referred to Anders et al. (2014).

Depending on the magnitude of differential stress and failure strength, an existing crack or fracture can slip before new cracks nucleate in the intact rock. Cataclasis is the mechanism by which faults accommodate deformation by grain fragmentation (microcracking), rotation and frictional sliding of grains, flaking of grains and grain transport (Engelder, 1974; Sibson, 1977; Peacock et al., 2016). These processes result in local ductile flow and strong grain size reduction causing the formation of fault gauge and fault rocks termed cataclasites (Fig. 1b). During cataclastic flow the rock's porosity can allow migration of fluids, which may precipitate cements from minerals such as calcite and quartz. These cements can later be deformed by cataclastic processes. Brittle deformation typically happens at low temperatures during diagenesis and low-grade metamorphism and is strongly controlled by fluid pressure. However, brittle deformation has also been described as a timedependent process that depends on temperature (e.g., Brantut et al., 2013). The formation of connected faults and fracture networks allows the circulation of fluids and the healing of fractures by filling with mineral precipitates to form veins (see review by Bons et al., 2012). Most rocks are mechanically anisotropic when they contain microcracks that form along specific crystal lattice directions, or due to the presence of bedding interfaces, cleavage 
planes or pre-existing fractures. In such cases brittle failure is controlled by the type, intensity and orientation of anisotropy (e.g., Donath, 1961; Peacock and Sanderson, 1992; Butler et al., 2008; Gomez-Rivas and Griera, 2012).

Certain minerals, such as calcite, plagioclase, quartz or gypsum, can deform by mechanical twinning when the action of stress results in the instantaneous formation of twin boundaries within grains (Fig. 1c) (Burkhard, 1993; Lacombe, 2010). A twin is a planar crystallographic defect separating two crystals that share a coherent interface with the same crystal lattice points in a symmetric way (e.g., Clayton, 2010). Once a twin is formed progressive deformation can create new twins elsewhere or deform the twinned rock portion by other mechanisms. Twinning generally occurs at low deformation temperatures, although it can also operate at higher metamorphic grades and is temperature dependent (Wenk et al., 2006). Since mechanical twinning can accommodate a very limited amount of strain, this mechanism normally co-exists with other deformation processes, such as brittle failure, pressure solution or dislocation creep. Twins in calcite have been widely used as paleopiezometers for stress determination in sedimentary basins and fold and thrust belts (Beaudoin and Lacombe, 2018). Kinking is similar to twinning but is not restricted to specific crystal planes, and therefore the formation of kink band boundaries is not easy to predict. Kinking also co-exists with other deformation mechanisms and is typical of highly anisotropic minerals such as phyllosilicates that have a strong tendency for basal slip (Kronenberg et al., 1990).

Dissolution-precipitation, also referred to as pressure-solution (Fig. 1d), is a deformation mechanism that operates by: (i) dissolution of minerals in a fluid phase at grain boundaries, especially where these are in contact, (ii) diffusion of the dissolved material to zones where stress is lower due to chemical potential gradients induced by the stress difference and (iii) precipitation in zones of lower stress, either locally (e.g., in strain 
shadows) or far away from the dissolution site (e.g., to form veins or as cement filling rock pores) (Robin 1978; Wheeler 1987). Pressure-solution is typical of systems operating at relatively low temperatures (i.e., during diagenesis and low-grade metamorphism), in the presence of fluids and in a range of differential stress, including relatively high differential stress. Stylolites are exemplary structures resulting from localised pressure solution along rough surfaces (Koehn et al., 2016; Toussaint et al., 2018). However, it is worth noting that pressure-solution can also operate in higher grade metamorphic conditions (e.g., Wintsch and Yi, 2002).

Ductility of rock is normally related to middle to lower crustal levels, where temperatures and lithostatic pressures are higher. Crystals deform internally when crystallographic defects (vacancies, interstitials and dislocations) migrate through the crystal and interact, resulting in permanent strain normally without brittle failure (Poirier, 1985). These processes are referred to as crystal plasticity. However, there are situations in which brittle and ductile deformation coexist (Mancktelow, 2008). Glide of dislocations in specific planes and along certain directions (termed slip systems) is the main mechanism of intracrystalline deformation (Fig. 1e). Each mineral has different slip systems, and whether dislocations glide or not along a specific slip system depends on the minimum amount of stress that is required to activate it (known as the critical resolved shear stress - CRSS), as well as on the local orientation and magnitude of the stress field. The CRSS required to activate a slip system is mainly controlled by temperature, in a way that the relative activity of the different slip systems of a mineral may change with the conditions at which deformation takes place. On top of temperature, stress, strain rate and presence of fluids also determine slip system activity. According to Orowan's equation, the strain rate of a material that deforms by dislocation glide depends on the Burgers vector (which accounts for the minimum magnitude and direction of lattice displacement caused by a dislocation in a crystal 
lattice), the dislocation density and their velocity (Orowan, 1948; Kocks et al., 1975). Pure glide of dislocations, without involving other deformation mechanisms, results in exponential flow laws (Karato, 2012 and references therein).

Dislocations can encounter obstacles while they migrate through the crystal lattice. These can be other dislocations or point defects, and can result in obstruction and pile up of dislocations behind the entangled ones, leading to higher stress concentration and strain hardening. Such situations make it more difficult for the rock to continue deforming and can potentially enhance embrittlement of the system. However, vacancies can migrate to dislocation lines, causing them to move out of their glide plane and allowing them to overcome obstacles by climbing over them (Weertman, 1955). This mechanism of dislocation glide with climb is referred to as dislocation creep, and is usually the dominant mechanism by which rocks in the ductile regime deform, and results in power-law flow laws. The rate of dislocation climb strongly depends on temperature, since it is controlled by how fast vacancies diffuse. Therefore, higher temperatures favour vacancy diffusion and climb of dislocations, resulting in rock softening.

Intracrystalline recovery and recrystallisation processes counteract dislocation glide and creep and cause a re-organisation of the subgrain and grain boundary network of a rock, changing the shape and size of grains and subgrains, as well as their crystallographic orientation (e.g., Urai et al., 1986; Hirth and Tullis, 1992; Humphreys and Hatherly, 2004). Intracrystalline recovery reduces the amount of internal strain energy caused by accumulation of dislocations and dislocation tangles by reducing their density (i.e., total length of dislocations per crystal volume) through processes such as: (i) annihilation of dislocations of opposite sign when they encounter each other, (ii) polygonisation by the formation of new subgrain boundaries (separating neighbour regions in which crystals on both sides present a certain misorientation) by the alignment of dislocations (Borthwick and Piazolo, 2010), (iii) 
climb of edge dislocations by vacancy diffusion and, (iv) cross-slip, when screw dislocations overcome obstacles by gliding onto a plane oriented oblique to the original plane along which they were gliding (de Bresser et al., 2002). Intracrystalline recovery processes are enhanced at higher temperature and can occur during deformation (competing with it) and continue when it has ceased to reduce dislocation density and internal strain energy.

Dynamic recrystallisation also counteracts the effects of dislocation glide and creep by causing the formation and movement of grain and subgrain boundaries (Urai et al., 1986; Passchier et al., 2005). Three dynamic recrystallisation mechanisms have been defined depending on temperature and stress: bulging (BLG), subgrain rotation (SGR), and grain boundary migration (GBM) recrystallisation (Urai et al., 1986; Hirth and Tullis, 1992). At relatively low temperature and high stress, when the mobility of grain boundaries is low, bulges can form when grain boundaries locally migrate into zones where crystals have high dislocation density. Bulges can evolve to form new small grains, either by the progressive increase of misorientation that leads to the formation of subgrain and eventually grain boundaries, or by the further local migration of the existing grain boundaries (Stipp et al., 2002). Subgrain rotation recrystallisation is a process by which migrating dislocations are added to subgrain boundaries in a way that crystals of neighbouring subgrains become progressively misoriented with regard to each other forming low-angle subgrain boundaries (Fig. 1f) (Pennock et al., 2005). Progressive strain increases this misorientation until the mismatch reaches a critical angle (normally from $10^{\circ}$ to $15^{\circ}$, depending on the mineral; Karato, 2012) and the subgrain boundary evolves to form a new, high-angle grain boundary. The addition of dislocations to subgrain boundaries requires that they climb across lattice planes, and therefore subgrain rotation recrystallisation requires higher temperatures than bulging recrystallisation. SGR causes strong grain size reduction. However, intracrystalline recovery counteracts SGR by producing subgrain coarsening by coalescence through rotation 
and alignment of the lattices of neighbouring subgrains (Gomez-Rivas et al., 2017). At higher temperatures grain boundaries become more mobile and can sweep though grains removing dislocations as well as subgrain boundaries, driven by a reduction of the stored strain energy and grain boundary energy. This process, termed grain boundary migration (Fig. 1g) (Guillopé and Poirier, 1979; Urai et al., 1986), leads to grain size increase with lobate grain boundaries. Grain boundary mobility depends on temperature and the presence of fluids and impurities. Small second-phase small particles, such as micas, reduce and can even prevent grain boundary migration by pinning grain boundaries (Herwegh et al., 2011). Recent studies reveal how GBM can significantly alter the activity of slip systems, even for highly anisotropic minerals (Llorens et al., 2016). Bulging, subgrain rotation and grain boundary migration recrystallisation correspond to the Regimes one, two and three of Hirth and Tullis (1992), respectively.

At higher temperatures, closer to the melting point of the rock-forming minerals, and when stresses are lower, the dominant deformation mechanism is diffusion creep. This is caused by the diffusion of vacancies through crystals when there is a gradient of vacancy concentration. There are two types of diffusion creep: (i) Coble creep occurs when vacancies diffuse along grain boundaries (Fig. 1h), while (ii) Nabarro-Herring creep operates when vacancies diffuse through the crystal lattice (Fig. 1i) (Nicolas and Poirier, 1976). NabarroHerring creep requires higher temperatures than Coble creep because the activation energy for vacancy diffusion through the crystal lattice is normally higher than that along grain boundaries. Grain boundary sliding is a deformation mechanism that can accommodate very high strains when grains can slide past each other. This process is assisted by diffusion mass transfer and also by pressure-solution and precipitation in the presence of fluids (Wheeler, 1992). Grain boundary sliding typically occurs at high temperatures and low stresses, but can also operate at lower temperatures when the fluid content is high and depending on the 
composition of the deforming rock (Urai and Spiers, 2007). This process is especially enhanced in polycrystalline aggregates with very small grain size. Superplasticity is a special term used for systems with a homogeneous and very small grain size that deform to high strain by dominant grain boundary sliding without achieving shape- or crystallographicpreferred orientations (Warren and Hirth, 2006). Diffusion creep (including Coble and Nabarro-Herring creep) as well as grain boundary sliding result in Newtonian flow, in a way that strain rate is linearly proportional to the magnitude of applied stress. However, unlike dislocation creep, diffusion creep is grain size sensitive so that flow rates increase with decreasing grain size.

Rock microstructures can further evolve after deformation ceases, if the rock is subjected to relative high temperature and a substantial amount of internal free energy is accumulated (in the form of dislocations, irregular grain boundaries, grain size variations, etc). The excess of energy will be reduced after deformation by processes like intracrystalline recovery (Borthwick et al., 2013) and grain boundary migration (Jessell et al., 2003) under static conditions (e.g., static recrystallisation Evans et al., 2001), which strongly depend on temperature and fluid content. Static grain growth increases the size of grains and results in smoothly curved grain boundaries with triple junctions with dihedral angles of $120^{\circ}$, while recovery reduces the dislocation density and therefore the number of grains and subgrains. As in the case of GBM during deformation, grain growth can be hindered by the presence of second phases and small particles, which may pin to grain boundaries making them less mobile.

An important aspect relevant in structural geology is that most rock-forming minerals present low crystalline symmetry and therefore they normally behave anisotropically in terms of mechanics and recrystallisation (Healy et al., 2019). For example, the orientations of slip systems able to accommodate deformation and their CRSSs are controlled by crystal 
symmetry and lattice dimension. The limitation of their activity during dislocation creep results in anisotropic behaviour when rocks undergo deformation and therefore result in the development of crystal preferred orientations (CPOs) (e.g., Urai et al., 1986). Additionally, the mobility of grain boundaries and diffusion are also anisotropic for some minerals (Schenk et al., 2006) and therefore recrystallisation processes also induce the development of anisotropy and lattice re-orientation. The mechanical properties of anisotropic rocks therefore can strongly vary through time.

The dependence of deformation mechanisms on temperature, stress and strain-rate allow using tools to infer the evolution of these parameters during rock deformation from the systematic analysis of microstructures (Ashby and Verrall, 1973). Deformation mechanism maps can be utilised to quantify the stress and temperature conditions under which deformation mechanisms are active and dominate for a given mineral (Fig. 1). These maps are normally built from a combination of experimental data, combined with observations of microstructures of natural rocks deformed at known temperature and stress, usually estimated from metamorphic mineral assemblages. Deformation mechanism maps can also include estimated curves for different strain rates, showing predicted flow laws (e.g., Poirier, 1985; Hirth et al., 2001; Kohlstedt and Hansen, 2001; Lu and Yiang, 2019). Since some of the main deformation mechanisms are grain-size dependent, maps for various grain sizes are normally built for the same system. Fig. 1 presents an idealised deformation mechanism map for a generic mineral, showing the differential stress and homologous temperature (i.e., normalised to its melting point temperature) at which each deformation mechanism dominates. It is worth noting that deformation mechanism maps show stress-temperature fields under which a certain deformation mechanism is dominant (i.e., results in the fastest strain rate for a given set of conditions), but they do not necessarily correlate with a specific microstructure. For example, a microstructure with CPO does not automatically mean that the study rock has not 
undergone Coble creep. Moreover, different deformation mechanisms can co-exist, and these maps only show fields of the dominant mechanism at a certain range of deformation conditions. The transition from one dominant mechanism to another is normally gradual, but these maps necessarily show sharp boundaries between the deformation mechanisms contributing the fastest strain rate.

Another widely-used tool for understanding the influence of pressure and temperature on rock deformation is the strength-depth diagram. These predict variations strength down through the lithosphere for given mineral compositions (e.g., dry or wet quartz, olivine, etc.), and by assuming a geothermal gradient, strain rate, grain size and stress field orientation (e.g., Brace and Kohlstedt, 1980; Kohlstedt et al., 1995; Stüwe, 2007). The depth directly relates to the temperature, according to the geothermal gradient, and is plotted against differential stress or the material strength. These diagrams show two curves that intersect: one for the brittle strength (with a nearly linear increase of strength with depth) and one for the strength of a rock deformed by dislocation creep. The brittle relationship (Byrelee's law) accounts for the shear stress required for a rock volume to slide along a fault, which depends on the normal stress. The ductile curve represents the decrease of the rock's strength with increasing temperature (i.e., with increasing depth). The rock will deform by the weakest available mechanism, which normally is brittle failure at shallow levels and low temperature and viscous flow at deeper levels and higher temperatures, with a brittle-to-ductile transition at the crossover point of the two strength-depth curves. These diagrams are useful and widely used, especially for developing understanding of lithosphere-scale deformation (e.g., Kusznir and Park, 1984, and many others since). There are limitations though: in general, these diagrams only use the two of the aforementioned deformation mechanisms, and temperaturedependent creep processes generally assume a single controlling phase. Much further work needs to be done to develop understanding of how complex rheologies inherent in 
polymineralic rocks vary through the lithosphere and during deformation (e.g., Handy et al., 2001).

\section{Contents of this volume}

This section summarises the contributions to this special issue, ordered from those analysing deformation processes occurring at high temperatures (starting with partially molten rocks) to articles reporting deformation at shallow crustal conditions (i.e., dominated by brittle failure).

Temperature changes and the presence of water control partial melting of rocks in the Earth's crust. The interaction between partial melting and rock deformation is crucial for understanding geodynamic processes, syn- and late-orogenic ductile flow of lower crust rocks in collision zones and rock exhumation during continental subduction. Three contributions in this special issue address the interaction between partial melting and rock deformation in lower crustal rocks.

Lee et al. (2018) analyse the interaction between partial melting and strain localisation with a systematic study of migmatites affected by shear zones in the Western Gneiss Region (Norway). They present a study based on fieldwork, microstructural and geochemical analyses to show how strain was partitioned during melting through stress-driven melt organisation and grain size reduction, and how the resulting system (migmatite and shear zone) froze without further shearing. This study illustrates a mechanism of syn-melt mylonite formation, implying that post-melt deformation in shear zones and significant melt loss by expulsion may not always take place, as is commonly thought.

Butler and Torvela (2018) propose a mechanism of pegmatite formation that resolves the pegmatite paradox. This enigma is based on the contradictory facts that many syn-tectonic granitic pegmatites preserve primary magmatic structures not affected by deformation, but at 
the same time the geometries of pegmatite bodies reveal that they normally appear deformed, showing more competent behaviour than their encasing rocks. The authors examine field relationships of pegmatites, host rocks and shear zones in Torrisdale (N Scotland), in combination with data from granitic melt solidification experiments. In their model, the high crystallisation rates of crystals in pegmatite body margins encapsulate residual melts, which could remain molten as a consequence of their enrichment in incompatible elements that act as crystallisation inhibitors. This mechanism explains how partially crystallised granitic melt can behave in a competent manner during deformation, implying that such intrusions would not weaken shear zones.

Llorens et al. (2019) present a numerical study of the mechanical behaviour and microstructures of partially molten rocks, focusing on analysing the competition between viscoplastic deformation and dynamic recrystallisation dominated by grain boundary migration. The results reveal two end-member regimes, which are related to the strain rate at which the system is deformed. The first regime is controlled by deformation and is characterised by large connected melt pockets favouring strain localisation, while the second one is dominated by recrystallisation and results in microstructures with disconnected melt pockets. This contribution also addresses the influence of the dihedral angle of different types of melt (e.g., basaltic, metallic), which is related to the composition of the partially molten rock and the bulk temperature.

Analysis of the microstructures and geochemistry of exposed rocks can be utilised to unravel the pressure and temperature at which they were deformed and metamorphosed. Three articles of this special issue present studies based on geothermometry and geothermobarometry in different tectonic settings.

Mazza et al. (2018) obtained detailed estimates of temperatures of metamorphism and deformation of the Moine and Sgurr Beag thrust sheets (Caledonides, N Scotland), with the 
aim of understanding the thermal history of the thrust sheets in the hinterland of the Scandian orogenic wedge. These authors studied samples from a series of outcrops in a transect cutting the thrust sheets. They estimate deformation temperatures using the quartz c-axis fabric opening angle thermometer and quartz recrystallisation regimes interpreted from rock fabrics. They utilise thermobarometry, pseudo-section modelling, and geochronology to unravel the timing and P-T conditions of metamorphism of pelitic rocks in the Sgurr Beag thrust sheet. The results reveal that Precambrian metamorphism peaked during the Knoydartian orogenic event and that deformation continued after that. The authors also discuss later metamorphism synchronous with Scandian thrusting.

Molli et al. (2018) present a tectonometamorphic study based on thermometry applied to the Alpi Apuane of the inner northern Apennines (NW Tuscany, Italy). They use Raman spectroscopy on carbonaceous material to analyse the variability of peak metamorphic temperatures in the different thrust units and how they relate to their deformation history. The results of this study support the hypothesis that the Alpi Apuane is a cold metamorphic core complex that underwent syn-orogenic exhumation during contraction with crustal thickening, with a well-preserved inverted metamorphism due to a cool paleothermal gradient. The authors also discuss how the system switched to a crustal thinning regime during the final stages of exhumation under mid-crustal conditions.

Cavalcante et al. (2018) constrain peak temperatures of mylonitization in a transpressive shear zone in the Ribeira orogenic belt (Brazil). They make use of the Titanium-in-quartz (TitaniQ) geothermobarometer on quartz and feldspar-rich rocks to estimate the thermal conditions during rock deformation and link them to the microstructures. They conclude that deformation took place in this shear zone at high temperature, resulting in structural softening during mylonite formation. Accordingly, quartz dynamically recrystallised by dominant grain boundary migration, followed by static grain growth and 
subgrain rotation recrystallisation. Despite the strong deformation, weak crystallographic preferred orientations (CPOs) of quartz crystals are interpreted to be related to diffusion processes that activated synchronously or after dislocation creep.

Rock deformation fabrics, crystal preferred orientations and strain localisation can develop in ductile rocks, partly controlled by the temperature at which the rock deforms. Several contributions of this special issues focus on the formation of these structures, based on field, experimental and numerical studies.

De Riese et al. (2019) present a numerical study of shear localisation in anisotropic rocks and compare the simulation results with the geometries of natural shear zones at Cap de Creus (Eastern Pyrenees, NE Spain). A series of simple shear models of a locally anisotropic, single-phase power-law rheology rock are analysed, focusing on quantifications of strain localisation patterns, crystal preferred orientations (CPOs) and the statistics of stress and strain rate. The simulations reveal that the degree of strain localisation in shear bands depends on the magnitude of anisotropy and stress exponent, and that there is a continuum between low and high strain. Highly anisotropic systems result in log-normal strain-rate frequency distributions with a heavy exponential tail. This observation supports the notion that anisotropy-controlled strain localisation is a self-similar process, and thus operates at multiple scales from mm-wide shear bands to km-scale shear zones.

The study of crystal preferred orientations was also the focus of the contribution by Craw et al. (2018), based on deformation experiments of natural anisotropic ice. This material has been widely used as an analogue for crustal rock deformation, and the study of polar icesheet deformation and recrystallisation has attracted significant attention by structural geologists during the last decade (Faria et al., 2014). Craw et al. (2018) deformed natural ice in axial compression at variable angles to an initial strong CPO at different strain rates. The cryo-electron backscatter diffraction (EBSD) analysis of the deformed samples indicates how 
the grain size distribution is not homogeneous in these experiments, with networks of small grains with weak CPOs surrounding zones of relic larger grains with strong CPOs. The authors interpret that subgrain rotation recrystallisation controlled formation of the recrystallised grain fraction, whose CPOs were weakened by grain boundary sliding (GBS). This process also affected the rotation of the large grains. These experiments reveal the complexity of interacting temperature-controlled deformation mechanisms, and how CPOs can completely change after low axial strain.

Papeschi et al. (2018) also focus on the study of strain localisation by unravelling the evolution of shear zones in the Calamita Schists of Elba (Italy). They observe well-exposed shear zones that formed in a relatively shallow crustal position during the Late Miocene. Strain localisation was coeval with high-grade contact metamorphism associated with intrusions, and resulted in the formation of a mylonitic foliation as well as $\mathrm{S}-\mathrm{C}$ structures. According to this study, cooling of the aureole resulted in strain partitioning between domains of competent relics and those in which soft shear bands formed by retrograde growth of phyllosilicates. A network of anastomosed C' shear bands resulted in the formation of complex foliation patters, and such shear bands acted as precursors for low-angle brittle faults and shear fractures, revealing a temperature-controlled coeval brittle-ductile deformation system.

Nassif et al. (2018) examine the structural evolution of part of the Neoarchean Abitibi greenstone belt (Ontario, Canada), an important orogenic gold province. They combine a detailed field study, including mapping and an analysis of cross-cutting relationships of structures and intrusions, with monazite-dating based on $\mathrm{U}-\mathrm{Pb}$ laser ablation, inductively coupled, plasma mass spectrometry. Their interpretation of structural evolution of the Garrison camp gold deposit invokes deformation having evolved from initial local shearing to distributed transtension between two deformation zones. Both behaviours resulted in ore 
deposition. Finally, the authors propose that local extension formed younger gold-bearing veins. $\mathrm{U}-\mathrm{Pb}$ dates indicate that most of the ore deposits formed after crystallization of a granitic stock.

Cochelin et al. (2018) present a novel multi-scale strain field analysis geostatistical approach to characterise the distribution of cleavage and stretching lineation patterns at multiple scales, and illustrate this with a study of the hot Variscan basement of the Pyrenees. The proposed method is based on variogram analysis and kriging interpolations and allows estimation of paleo-strain fields from foliation and lineation trajectories. The results indicate that pure shear deformation conditions existed in the axial zone of the Pyrenees during N-Soriented convergence of the European and Iberian plates. Moreover, cleavage and lineation patterns indicate strain partitioning between the upper Earth's upper crust, which underwent homogeneous thickening, and the mid- to lower Earth's crust, which was hotter and experienced horizontal flow. The effect of intrusions in the upper crust can also be recognised with this method, which reveals strain localisation and the formation of transpressional shear zones around plutons and gneiss domes.

Two-phase rocks, such as conglomerates composed of pebbles embedded in a finergrained matrix, have been widely used to unravel the tectonic history of rocks. Depending on their composition and the rock temperature, pebbles can behave as effectively passive, deformable or effectively rigid, determining the rheology of the rock and resulting deformation structures. Through two-dimensional linear and non-linear viscous numerical simulations Ran et al. (2018) analyse how different types of ductile conglomerates can be used for strain analysis. The models study a wide range of conglomerate systems, with varying pebble concentration, viscosity ratios between pebbles and the matrix and the stress exponent for linear or power-law viscous rheology. Using systematic series of conglomerate deformation, the authors provide a plot of pebble mean aspect ratio $\left(R_{f}\right)$ versus orientation 
$(\square)$ that can be used to estimate conglomerate deformation behaviour and the amount of bulk strain. As a demonstration, the method is applied to estimate finite strain and the rheology of deformed conglomerates in the Wutai Mountains, North China Craton.

There are complex feedback relationships between rock deformation processes and the transport of aqueous fluids and magma in the Earth's crust. Rock deformation structures control fluid migration, and at the same time, fluids and magma influence the dominant deformation mechanisms, both in ductile and brittle conditions. Three articles of this special issue address how structures control fluid flow and vice versa.

The injection and cooling of magma in relative shallow parts of the Earth's crust can result in the intrusion of dykes and thus local extension and mode I or II fractures. Through two-dimensional coupled lattice spring and hydrodynamics simulations Koehn et al. (2019) study how fractures and collapse grabens can form in kilometre-scale rift systems. A comparison of scenarios with extension associated with either tectonically-induced stress or dyking, or a combination of both, allows for the visualisation of the patterns of mode I and II fracture formation and their downwards or upwards propagation in rift systems. Their models show how hybrid systems, with combined tectonic extension and dyking, undergo an evolution from initial fault nucleation and propagation, followed by the development of conjugate fault networks and, eventually, to the collapse of rhomboid blocks.

Also focusing on rift systems, Hollinsworth et al. (2019) present a detailed petrographic and structural analysis of permeability and fluid-rock interactions of a basement fault zone in the East African Rift. The Bwamba Fault zone, which affects granitic host rocks and caused re-activation of older fabrics, defines a flank of the Rwenzori Mountains Horst (Uganda). It is found that permeability in such crystalline rocks was controlled by tectonic structures, such as fractures of different scales and cataclasite seams. Different fluid circulation events are identified from the veins and other precipitates, in a system where a 
basement normal fault evolved to form a rift basin margin fault. The authors discuss two main models for fluid flow, in which fluids circulate co-seismically, when the fault was active, and also after permeable pathways already existed, in a post-seismic scenario.

Galetto et al. (2018) also present and discuss structural controls on fluid flow, by studying faults and fracture networks of the Domuyo volcano in the Southern Andes (Argentina), a high-enthalpy geothermal system associated with active volcanoes. These high-temperature geothermal fields are located along a volcanic arc related to the subduction of the oceanic Nazca slab beneath the South American plate. Based on the combination of remote sensing analysis and collection of structural data in the field, this study interprets how flow of meteoric, crustal and magmatic fluids is controlled by the recent reactivation of preexisting basement structures as normal faults that accommodate regional extensional and transtensional stresses.

Rocks in the shallow crust tend to deform by a combination of folding and fracturing when they are subjected to tectonic compression. Basa et al. (2019) present a field study of fracture and vein formation during the progressive evolution of a fold and thrust belt in the Main Boundary Thrust sheet of the frontal segment of the Arunachal Lesser Himalaya. By observing the orientations and cross-cutting relationships of fractures at multiple scales they unravel which fracture sets formed before, during and after folding. They also find that fracture spacing follows a power-law distribution, but with scale-dependent clustering in the case of fractures oriented at a high angle to bedding.

Gambino et al. (2019) also study the interplay between folding and other deformation structures, focusing on deformation bands. They statistically analyse the orientation and geometry of deformation bands in Miocene Numidian sandstones (Sicily), which underwent shallow burial, and also study samples with petrographic and electronic microscopy, X-ray microtomography and quantify porosities. They observe compaction and shear deformation 
bands, which present a significantly reduced porosity when compared to the intact host sandstones. Deformation band orientations are consistent with models for fracture formation during shallow-burial folding, and are arranged in two distinct populations.

Mechanical anisotropy is a key factor that controls the formation of deformation structures. Menezes and Lempp (2018) carry out triaxial compression tests to understand how anisotropy influences the mechanical behaviour and variations of physical properties of Bunter sandstones. They quantify fracture patterns and collect measurements of permeability, compressive strength, Young's modulus, mechanical work during the pre-failure stage and ultrasonic velocities on a series of water-saturated samples. The results indicate that properties vary depending on whether they are measured parallel or perpendicular to bedding. Additionally, the authors also interpret that the effects of anisotropy are generally enhanced with an increase of effective pressure.

The communications presented at the DRT-2017 conference, as well as the articles published in this special volume, are excellent examples of recent developments in the fields of structural geology, deformation mechanisms, rheology and tectonics. The improvement of existing techniques and the development of new ones during the last few decades are leading to compelling advances in our understanding of the formation of tectonic structures and rock deformation processes (also see the Journal of Structural Geology $40^{\text {th }}$ anniversary special issue; Hippert et al., 2019). Future trends that will likely inspire this field of research will focus on understanding: (i) geological processes at multiple scales, from the scale of singlecrystal defects to that of tectonic plates, (ii) the dynamics of rock deformation processes, (iii) controls on the variations of the rheology of the lithosphere, (iv) the behaviour of fault zones and how they relate to seismicity, (v) the interplay between rock deformation processes, geofluids and mineral reactions, and (vi) the interactions of tectonics and Earth-surface processes, among other aims (see Huntington et al., 2018 for a complete discussion on future 
trends in tectonics). Future research will also likely be motivated not only by our ambition to understand how our planet works, but also by societal challenges such as the exploration of raw materials, the supply of clean and safe energy and the mitigation of natural hazards. Our knowledge of structural geology and tectonics has always been based on the careful observation and interpretation of structures in the field, and thus fieldwork must continue to form the foundation of our research and the frame where most research questions are formulated. It is thus essential that we preserve our geological heritage for future generations.

\section{Acknowledgements}

We thank Bill Dunne for his work as Journal of Structural Geology overseeing editor, and to all the reviewers of manuscripts submitted to this special issue. We gratefully acknowledge Richard D. Law, Paul D. Bons, Albert Griera and Maria-Gema Llorens for reviewing this article prior to submission. The programme, abstract and field excursion guides for the DRT-2017 Inverness conference are available at: https://www.abdn.ac.uk/geosciences/events/downloads-1112.php.

\section{References}

Anders, M.H., Laubach, S.E., and Scholz, C.H. 2014. Microfractures: A review. Journal of Structural Geology, 69, 377-394.

Ashby, M.F. and Verrall, R.A. 1973. Diffusion-accommodated flow and superplasticity. Acta Metallurgica, 21, 149-163.

Basa, A., Ahmed, F., Bhattacharyya, K., and Roy, A. 2019. Evolution and characterization of fracture patterns: Insights from multi-scale analysis of the Buxa dolomite in the Siang Valley, Arunachal Lesser Himalayan fold-thrust belt. Journal of Structural Geology, $123,54-66$. 
Beaudoin, N., Koehn, D., Lacombe, O., Lecouty, A., Billi, A., Aharonov, E., and Parlangeau, C. 2016. Fingerprinting stress: Stylolite and calcite twinning paleopiezometry revealing the complexity of progressive stress patterns during folding - The case of the Monte Nero anticline in the Apennines, Italy. Tectonics, 35, 1687-1712.

Beaudoin, N. and Lacombe, O. 2018. Recent and future trends in paleopiezometry in the diagenetic domain: Insights into the tectonic paleostress and burial depth history of fold-and-thrust belts and sedimentary basins. Journal of Structural Geology, 114, 357365.

Blenkinsop, T.G. 2000. Deformation microstructures and mechanisms in minerals and rocks. Kluwer Academic Publishers, Dordrecht, 150 pp.

Bons, P.D., Elburg, M.A. and Gomez-Rivas, E. 2012. A review of the formation of tectonic veins and their microstructures. Journal of Structural Geology, 43, 33-62.

Borthwick, V.E., and Piazolo, S. 2010. Post-deformational annealing at the subgrain scale: Temperature dependent behaviour revealed by in-situ heating experiments on deformed single crystal halite. Journal of Structural Geology, 32, 982-996.

Borthwick, V.E., Piazolo, S., Evans, L., Griera, A. and Bons, P.D. 2013. What happens to deformed rocks after deformation? A refined model for recovery based on numerical simulations. Geological Society of London Special Publication, 394, 215-234.

Brace, W.F., and Kohlstedt, D.L. 1980. Limits on lithospheric stress imposed by laboratory experiments. Journal of Geophysical Research, 85, 6348-6252.

Brantut, N., Heap, M.J., Meredith, P.G. and Baud, P. 2013. Time-dependent cracking and brittle creep in crustal rocks: A review. Journal of Structural Geology, 52, 17-43.

Brown, M. 1993. P-T-t evolution of orogenic belts and the causes of regional metamorphism. Journal of the Geological Society, 150, 227-241. 
Burkhard, M. 1993. Calcite twins, their geometry, appearance and significance as stressstrain markers and indicators of tectonic regime: a review. Journal of Structural Geology, 15, 351-368.

Butler, R.W.H. and Torvela, T. 2018. The competition between rates of deformation and solidification in syn-kinematic granitic intrusions: Resolving the pegmatite paradox. Journal of Structural Geology, 117, 1-13.

Butler, R.W.H., Bond, C.E., Shipton, Z.K., Jones, R.R. and Casey, M. 2008. Fabric anisotropy controls faulting in the continental crust. Journal of the Geological Society, London, 165, 449-452.

Cavalcante, C., Lagoeiro, L., Fossen, H., Egydio-Silva, M., Morales, L.F.G., Ferreira, F., and Conte, T. 2018. Temperature constraints on microfabric patterns in quartzofeldsphatic mylonites, Ribeira belt (SE Brazil). Journal of Structural Geology, 115, 243-262.

Christie, J.M., Griggs, D.T., and Carter, N.L. 1964. Experimental evidence of basal slip in quartz. The Journal of Geology, 72, 734-756.

Clayton, J.D. 2010. Mechanical Twinning in Crystal Plasticity. In: Nonlinear Mechanics of Crystals. Solid Mechanics and Its Applications, vol 177. Springer, Dordrecht.

Cochelin, B., Gumiaux, C., Chardon, D., Denèle, Y., and Le Bayon, B. 2018. Multi-scale strainfield analysis using geostatistics: Investigating the rheological behavior of the hot Variscan crust of the Pyrenees (Axial Zone). Journal of Structural Geology, 116, 114-130.

Craw, L., Qi, C., Prior, D.J., Goldsby, D.L., and Kim, D. 2018. Mechanics and microstructure of deformed natural anisotropic ice. Journal of Structural Geology, 115, 152-166.

Donath, F.A. 1961. Experimental study of shear failure in anisotropic rocks. Geological Society of America Bulletin, 72(6), 985-989. 
de Bresser, J.H.P., Evans, B. and Renner, J. 2002. On estimating the strength of calcite rocks under natural conditions. In: De Meer, S., Drury, M.R., de Bresser, J.H.P. and Pennock, G.M. (eds), Deformation mechanisms, rheology and tectonics: current status and future perspectives. Geological Society of London Special Publication, 200, 309329.

de Riese, T., Evans, L., Gomez-Rivas, E., Griera, A., Lebensohn, R.A., Llorens, M.-G., Ran, H., Sachau, T., Weikusat, I., and Bons, P.D. 2019. Shear localisation in anisotropic, non-linear viscous materials that develop a CPO: A numerical study. Journal of Structural Geology, 124, 81-90.

Engelder, J.T., 1974. Cataclasis and the generation of fault gouge. Geological Society of America Bulletin, 85, 1515-1522.

Evans M.A., and Dunne, W.M. 1991. Strain factorization and partitioning in the North Mountain thrust sheet, central Appalachians, USA. Journal of Structural Geology, 13, $21-36$

Evans, B., Renner, J. and Hirth, G. 2001. A few remarks on the kinetics of static grain growth in rocks. International Journal of Earth Sciences, 90, 88-103.

Faria, S.H., Weikusat, I., and Azuma, N. 2014. The microstructure of polar ice. Part II: State of the art. Journal of Structural Geology, 61, 21-49.

Fulljames, R.J., Zijerverld, L.J. and Franssen, R.C.M.W. 1997. Fault seal processes: synthetic analysis of fault seals over geological and production time scales. In: Moller, P. and Koestler, A.G. (Eds.): Hydrocarbon Seals: Importance for Exploration and Production, NPF Special Publication, 7, pp. 51-59.

Galetto, A., García, V., and Caselli, A. 2018. Structural controls of the Domuyo geothermal field, Southern Andes (36 38'S), Argentina. Journal of Structural Geology, 114, 7694. 
Gambino, S., Fazio, E., Maniscalco, R., Punturo, R., Lanzafame, G., Barreca, G., and Butler, R.W.H. 2019. Fold-related deformation bands in a weakly buried sandstone reservoir analogue: A multi-disciplinary case study from the Numidian (Miocene) of Sicily (Italy). Journal of Structural Geology, 118, 150-164.

Gomez-Rivas, E. and Griera, A. 2012. Shear fractures in anisotropic ductile materials: an experimental approach. Journal of Structural Geology, 34, 61-76.

Gomez-Rivas, E., Griera, A., Llorens, M.-G., Bons, P.D., Lebensohn, R. and Piazolo, S. 2017. Subgrain rotation recrystallization during shearing: insights from full-field numerical simulations of halite polycrystals. Journal of Geophysical Research Solid Earth, 122 (11), 8810-8827.

Griffith, A.A. 1921. VI. The phenomena of rupture and flow in solids. Philosophical Transactions of the Royal Society, A221, 163.

Griggs, D. 1940. Experimental flow of rocks under conditions favoring recrystallization. Bulletin of the Geological Society of America, 51, 1001-1022.

Guillopé, M. and Poirier, J.P. 1979. Dynamic recrystallization during creep of singlecrystalline halite: an experimental study. Journal of Geophysical Research Solid Earth, 84, 5557-5567.

Handy, M.R., Braun, J., Brown, M., Kukowski, N., Paterson, M.S., Schmid, S.M., Stöckhert, B., Stüwe, K., Thompson, A.B., and Wosnitza, E. 2001. Rheology and geodynamic modeling: The next step forward. In: Dresen, G. and Handy, M.R. (Eds.), Deformation Mechanisms, Microstructures and Rheology. International Journal of Earth Sciences, 90(1), 149-156.

Healy, D., Rizzo, R.E., Cornwell, D.G., Farrell, N.J.C., Watkins, H., Timms, N.E., GomezRivas, E. and Smith, M. 2017. FracPaQ: a MATLAB toolbox for the quantification of fracture patterns. Journal of Structural Geology, 95, 1-16. 
Healy, D., Timms, N.E., and Pearce, M.A. 2019. The variation and visualisation of elastic anisotropy in rock forming minerals, Solid Earth Discussions, https://doi.org/10.5194/se-2019-168, in review.

Herwegh, M., Linckens, J., Ebert, A., Berger, A. and Brodhag, S.H. 2011. The role of second phases for controlling microstructural evolution in polymineralic rocks: A review. Journal of Structural Geology, 33, 1728-1750.

Hippert, J., Alsop, G.I., Dunne, W., Passchier, C.W. and Takesita, T. 2019. Back to the Future: 40 years of Structural Geology and beyond. Journal of Structural Geology, $125,1-2$.

Hirth, G. and Tullis, J. 1992. Dislocation creep regimes in quartz aggregates. Journal of Structural Geology, 14, 145-159.

Hirth, G., Teyssier, C., Dunlap, W.J. 2001. An evaluation of quartzite flow laws based on comparisons between experimentally and naturally deformed rocks. International Journal of Earth Sciences, 90, 77-87.

Hobbs, B.E. and Ord, A. 2015. Structural geology: the mechanics of deforming metamorphic rocks (first ed.), Elsevier, Amsterdam, 680 pp.

Hollinsworth, A.D., Koehn, D., Dempster, T.J., and Aanyu, K. 2019. Structural controls on the interaction between basin fluids and a rift flank fault: Constraints from the Bwamba Fault, East African Rift. Journal of Structural Geology, 118, 236-249.

Humphreys, F.J. and Hatherly, M. 2004. Recrystallization and related annealing phenomena. Third edition, Elsevier Ltd, Oxford, 658 pp.

Huntington, K.W., and Klepeis, K.A., with 66 community contributors. 2018. Challenges and opportunities for research in tectonics: understanding deformation and the processes that link Earth systems, from geologic time to human time. A community vision 
document submitted to the U.S. National Science Foundation. University of Washington, $84 \mathrm{pp}$.

Jessell, M.W., Kostenko, O., Jamtveit, B. 2003. The preservation potential of microstructures during static grain growth. Journal of Metamorphic Geology, 21, 481-491.

Karato, S. 2012. Deformation of Earth Materials: An Introduction to the Rheology of Solid Earth. Cambridge University Press, 482 pp.

Kocks, U.F., Argon, A.S., Ashby, M.F., 1975. Thermodynamics and kinetics of slip, Progress in materials science, 19. Pergamon Press Ltd, $291 \mathrm{pp}$.

Koehn, D., Pataki-Rood, M., Beaudoin, N., Chung, P., Bons, P.D. and Gomez-Rivas, E. 2016. A new stylolite classification scheme to estimate compaction and local permeability variations. Sedimentary Geology, 346, 60-71.

Koehn, D., Steiner, A., and Aanyu, K. 2019. Modelling of extension and dyking-induced collapse faults and fissures in rifts. Journal of Structural Geology, 118, 21-31.

Kohlstedt, D.L., Evans, B. and Mackwell, S.J. 1995. Strength of the lithosphere:

constraints imposed by laboratory experiments. Journal of Geophysical Research, 100, $17587-17602$.

Kohlstedt, D.L. and Hansen, L.N. 2015. 2.18 - Constitutive equations, rheological behavior, and viscosity of rocks. In G. Schubert (Ed.), Treatise on Geophysics (2nd edition), Elsevier, pp. 441-472.

Kronenberg, A.K., Kirby, S.H. and Pinkston, J. 1990. Basal slip and mechanical anisotropy of biotite. Journal of Geophysical Research, 95 (B12), 19257-19278.

Kusznir, N.J. and Park, R.G., 1984. Intraplate lithosphere deformation and the strength of the lithosphere. Geophysical Journal International, 79, 513-538. 
Lacombe, O. 2010. Calcite twins, a tool for tectonic studies in thrust belts and stable orogenic forelands. Oil and Gas Science and Technology - Revue d'IFP Energies nouvelles, Institut Français du Pétrole, 65(6), 809-838.

Lapworth, C. 1884. On the structure and metamorphism of the rocks of the Durness-Eriboll district. Proceedings of the Geologists' Association, 8, 438-442.

Law, R.D., and Johnson, M.R.W. 2010. Microstructures and crystal fabrics of the Moine thrust zone and Moine nappe: history of research and changing tectonic interpretations. In: Law, R.D., Butler, R.W.H., Holdsworth, R.E., Krabbendam, M. and Strachan, R. (eds.). Continental tectonics and mountain building: the legacy of Peach and Horne. Geological Society of London Special Publication, 335, 443-503.

Lee, A.L., Torvela, T., Lloyd, G.E., and Walker, A.M. 2018. Melt organisation and strain partitioning in the lower crust. Journal of Structural Geology, 113, 188-199.

Lister, G.S., Williams, P.F., Zwart, H.J. and Lisle, R.J. (eds), 1977. Fabrics, microstructures and microtectonics. Tectonophysics 39(1-3), 1-487.

Llorens, M.-G., Griera, A., Bons, P.D., Roessiger, J., Lebensohn, R., Evans, L.A. and Weikusat, I. 2016. Dynamic recrystallisation of ice aggregates during co-axial viscoplastic deformation: a numerical approach. Journal of Glaciology, 62(232), 359377.

Llorens, M.-G., Gomez-Rivas, E., Ganzhorn, A.-C., Griera, A., Steinbach, F., Roessiger, J., Labrousse, L., Walte, N., Weikusat, I., and Bons, P.D. 2019. The effect of dynamic recrystallisation on the rheology and microstructures of partially molten rocks. Journal of Structural Geology, 118, 224-235.

Lu, L.X., and Jiang, D. 2019. Quartz flow law revisited: The significance of pressure dependence of the activation enthalpy. Journal of Geophysical Research: Solid Earth, 124, 241-256. 
Mancktelow, N.S. Interaction between brittle fracture and ductileflow during crustal deformation. 2008. Bollettino Della Societa Geologica Italiana, 127, 217-220.

Mazza. S.E., Mako, C., Law, R.D., Caddick, M.J., Krabbendam, M., and Cottle, J. 2018. Thermobarometry of the Moine and Sgurr Beag thrust sheets, northern Scotland. Journal of Structural Geology, 113, 10-32.

Mendum, J.R, Barber, A.J., Butler, R.W.H., Flinn, D., Goodenough, K.M., Krabbendam, M., Park, R.G. and Stewart, A.D. (eds). 2009. Lewisian, Torridonian and Moine rocks of Scotland. Geological Conservation Review Series, volume 34, Joint Nature Conservation Committee, Peterborough, pp. 721.

Menezes, F.F., and Lempp, C. 2018. On the structural anisotropy of physical and mechanical properties of a Bunter Sandstone. Journal of Structural Geology, 114, 196-205.

Molli, G., Vitale Brovarone, A., Beyssac, O. and Cinquini, I. 2018. RSCM thermometry in the Alpi Apuane (NW Tuscany, Italy): New constraints for the metamorphic and tectonic history of the inner northern Apennines. Journal of Structural Geology, 113, 200-216.

Nassif, M.T., Kuiper, Y.D., Goldfarb, R.J., Monecke, T. and Holm-Denoma, C.S. 2018. Structural evolution of a gold-bearing transtensional zone within the Archean Porcupine-Destor deformation zone, southern Abitibi greenstone belt, eastern Ontario, Canada. Journal of Structural Geology, 117, 203-218.

Nicolas, A. and Poirier, J.P. 1976. Crystalline plasticity and solid state flow in metamorphic rocks. Jokn Wiley \& Sons, London, 444 pp.

Orowan, E., 1948. Discussion in symposium on internal stresses in metals and alloys. Institute of Metals, London, p. 451. 
Papeschi, S., Musumeci, G., and Mazzarini, F. 2018. Evolution of shear zones through the brittle-ductile transition: The Calamita Schists (Elba Island, Italy). Journal of Structural Geology, 113, 100-114.

Passchier C.W. and Trouw R.A.J. 2005. Microtectonics. Heidelberg, Springer, 366 pp.

Peacock, D.C.P. and Sanderson, D.J. 1992. Effects of layering and anisotropy on fault geometry. Journal of the Geological Society of London, 149, 793-802.

Peacock, D.C.P., Nixon, C.W., Rotevatn, A., Sanderson, D.J. and Zuluaga, L.F. 2016. Glossary of fault and other fracture networks. Journal of Structural Geology, 92, 1229.

Pennock, G.M., Drury, M.R. and Spiers, C.J. 2005. The development of subgrain misorientations with strain in dry synthetic $\mathrm{NaCl}$ measured using EBSD. Journal of Structural Geology, 27, 2159-2170.

Poirier, J.P. 1985. Creep of crystals: high-temperature deformation processes in metals, ceramics and minerals. Cambridge University Press.

Ran, H., Bons, P.D., Wang, G., Steinbach, F., Finch, M.A., Griera, A., Gomez-Rivas, E., Llorens, M.-G., Ran, S., Liang, X., and Zhou, J. 2018. High-strain deformation of conglomerates: Numerical modelling, strain analysis, and an example from the Wutai Mountains, North China Craton. Journal of Structural Geology, 114, 222-234.

Robin, P.Y. 1978. Pressure solution at grain-to-grain contacts. Geochimica et Cosmochima Acta, 42, 1383-1389.

Rutter, E.H., 1983. Pressure solution in nature, theory and experiment. Journal of the Geological Society, 140(5), pp.725-740.

Schenk, O., Urai, J.L., and Piazolo, S. 2006. Structure of grain boundaries in wet, synthetic polycrystalline, statically recrystallizing halite - evidence from cryo-SEM observations. Geofluids, 6, 93-104. 
Sibson, R.H. 1977. Fault rocks and fault mechanisms. Journal of the Geological Society of London, 133, 191-213.

Sorby, H.C. 1858. On the microscopical structure of crystals, indicating the origin of rocks and minerals. Quarterly Journal of the Geological Society, London,14, 453-500.

Stipp, M., Stünitz, H., Heilbronner, R. and Schmid, S.M. 2002. The eastern Tonale fault zone: a "natural laboratory" for crystal plastic deformation of quartz over a temperature range from 250 to $700{ }^{\circ} \mathrm{C}$. Journal of Structural Geology, 24, 1861-1884.

Stüwe, K. 2007. Geodynamics of the lithosphere: quantitative description of geological problems. 2nd edition, Springer-Verlag, Berlin, Heidelberg, Dordrecht, pp. 493.

Teall, J.J.H. 1885. The metamorphism of a dolerite into hornblende schist. Quarterly Journal of the Geological Society, London, 41, 133-144.

Teall, J.J.H. 1918. Dynamic metamorphism: a review, mainly personal. Proceedings of the Geologists' Association, 29, 1-15.

Toussaint, R., Aharonov, E., Koehn, D., Gratier, J.-P, Ebner, M., Baud, P., Rolland, A. and Renard, F. 2018. Stylolites: A review. Journal of Structural Geology, 114, 163-195.

Tullis J.A., Christie J. M., and Griggs D. T. 1973. Microstructures and preferred orientations of experimentally deformed quartzites. Geological Society of America Bulletin 84, 297-314.

Urai, J.L., Means, W.D. and Lister, G.S. 1986. Dynamic recrystallization of minerals. In: Heard, H.C. and Hobbs, B.E. (eds), Mineral and rock deformation: laboratory studies, the Paterson volume. Geophysical Monograph Series, 36, 161-200, American Geophysical Union, Washington DC.

Urai, J.L. and Spiers, C.J. 2007. The effect of grain boundary water on deformation mechanism and rheology of rocksalt during long-term deformation. In: Wallner, M., 
Lux, K.-H., Minkley, W. and Hardy, H. (eds), The mechanical behaviour of salt understanding of THMC processes in salt. Taylor \& Francis, London, pp 149-158.

Warren, J.M. and Hirth, G. 2006. Grain size sensitive deformation mechanisms in naturally deformed peridotites. Earth and Planetary Science Letters, 248, 423-435.

Weertman, J. 1955. Theory of steady-state creep based on dislocation climb. Journal of Applied Physics 26:10, 1213-1217.

Wenk, H.R., Rybacki, E., Dresen, G. Lonardelli, I., Barton, N., Franz, H. and Gonzalez, G. 2006. Dauphiné twinning and texture memory in polycrystalline quartz. Part 1: Experimental deformation of novaculite. Physics and Chemistry of Minerals 33, 667.

Wheeler, J. 1987. The significance of grain-scale stresses in the kinetics of metamorphism. Contributions to Mineralogy and Petrology, 17, 397-404.

Wheeler, J. 1992. Importance of pressure solution and Coble creep in the deformation of polymineralic rocks. Journal of Geophysical Research Solid Earth, 97, 4579-4586.

Wheeler, J. 2018. The effects of stress on reactions in the Earth: sometimes rather mean, usually normal, always important. Journal of Metamorphic Geology, 36(4), 439-461.

White, S.H. 1973. Syntectonic recrystallization and texture development in quartz. Nature $244,276-278$.

Wintsch, R.P. and Yi, K. 2002. Dissolution and replacement creep: a significant deformation mechanism in mid-crustal rocks. Journal of Structural Geology, 24, 1179-1193.

\section{Figure captions}

Figure 1. Idealised deformation mechanism map, showing which deformation mechanism dominates according to differential stress and homologous temperature (i.e., normalised to the mineral's melting point). Note that these diagrams are built for a specific mineral and a 
given grain size, and they normally display strain rate contours. The axes are not to scale. (a) Sketch representing a fracture network in a bedding plane of the McDonald limestone (Carboniferous coal-bearing fluvio-deltaic rocks) in the Spireslack opencast coal pit. This figure is based on an aerial photo by Healy et al. (2017). (b) Cataclastic fault gouge in sandstone. This drawing is drawn from a scanning electron microscope photo of Fulljames et al. (1997). (c) Calcite deformation twins. Drawing based on a photo of Evans and Dunne (1991). (d) Sketch of an oolitic grainstone affected by dissolution-precipitation. Material is dissolved along the pressure-solution seams and reprecipitates in the form of cement in pressure shadows. (e) Sketch representing dislocations gliding along a slip system in a crystal. (f) Polycrystal with grain boundaries (solid lines) and subgrain boundaries (dashed lines). Grey tones represent different crystallographic orientations that define subgrains. HAGB and LAGB refer to high-angle and low-angle grain boundaries, respectively. Drawing based on a numerical simulation presented in Gomez-Rivas et al. (2017). (g) Sketch showing how grain boundary migration operates. Two neighbour grains have different dislocation densities, as represented by different colours. The difference in dislocation density is the driving force that causes migration of the boundary from the grain with low dislocation density to that with a higher one. This process reduces the dislocation density of the swept area. The lower part of the sketch shows grain boundary migration driven by reduction of the grain boundary length. Figure modified from Llorens et al. (2016). (h) Coble creep in a polycrystal, showing how vacancies migrate along grain boundaries. (i) Nabarro-Herring creep, with vacancies migrating through the crystal lattice. 


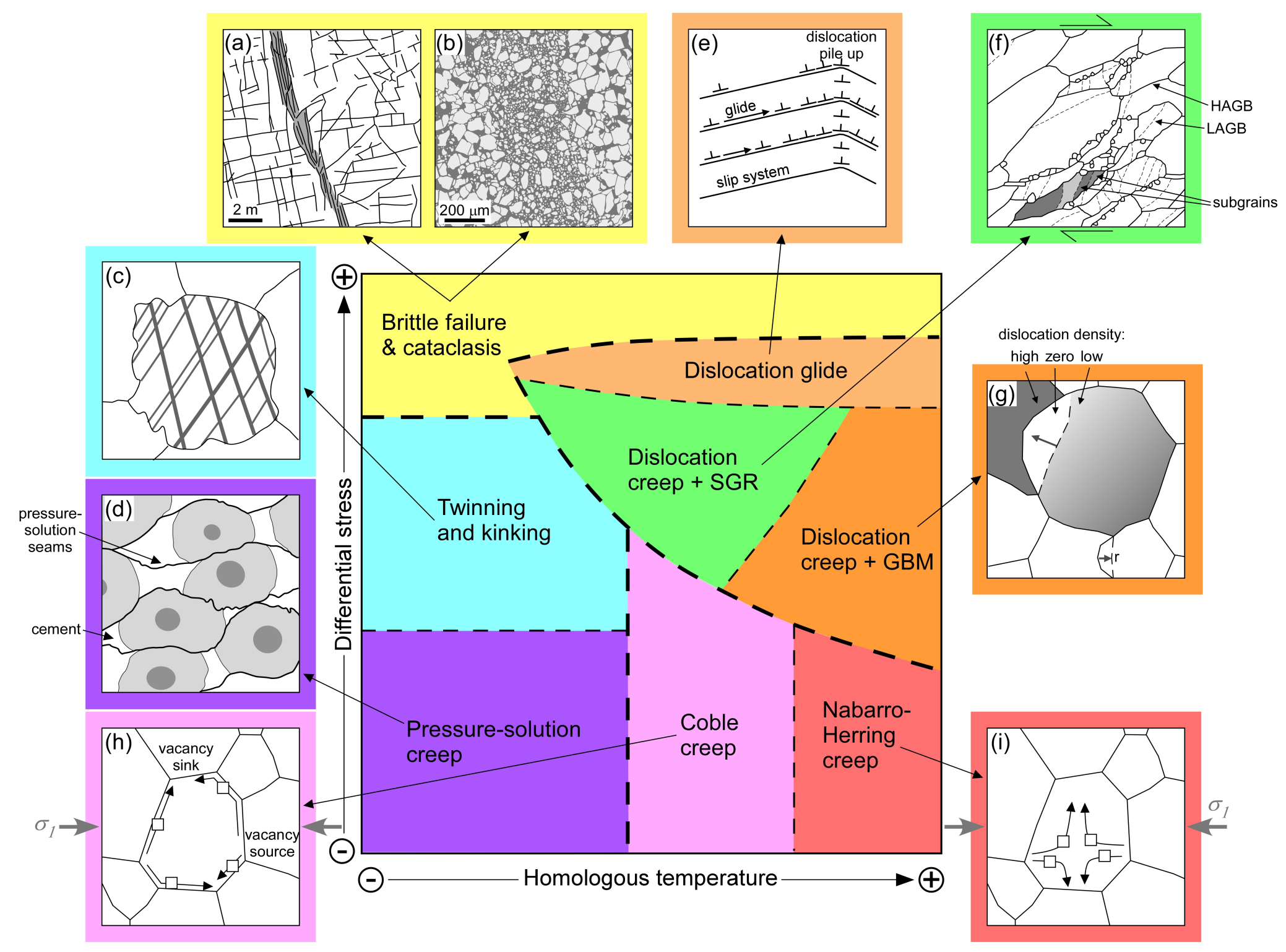




\section{Declaration of interests}

૫ The authors declare that they have no known competing financial interests or personal relationships that could have appeared to influence the work reported in this paper.

$\square$ The authors declare the following financial interests/personal relationships which may be considered as potential competing interests:

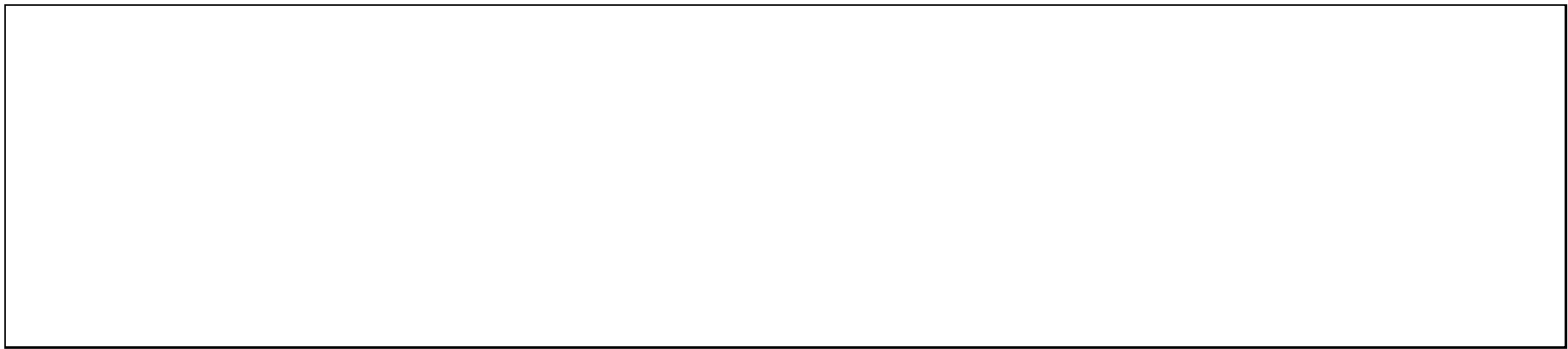

